\title{
Study on Teaching Method of Advanced Math under the Flipped Classroom
}

\author{
Kaibao Wang \\ Dongchang College of Liaocheng University, Shandong Liaocheng, 252000
}

Keywords: flipped classroom, advanced math, teaching practice

\begin{abstract}
As a newly-emerging teaching mode, flipped classroom has been paid attention to by educators. In the case of teaching practices of flipped classroom in advanced math, design module of flipped classroom has been explored and teaching effectiveness of practices has also been analyzed and considered.
\end{abstract}

\section{Introduction}

In accordance with Ten Years' Development Plan of Education Informatization (2011-2020), the development of teaching informatization should be led by innovation in education ideas, based on resource with high quality and the construction of learning environment related to informatization and should be as a core of learning styles and innovation in education modes. The rise of MOOC, flipped classroom and mixed teaching in recent years has conformed to the teaching reform and provided new ideas for teaching.

Flipped classroom is a new teaching mode that learning sequence in and out of classroom is readjust and students are made to independently finish basic learning content and information precourse. Meanwhile, in order to make students have access to more deep understanding for content, more deep tasks and practices are completed in class by communication and collaboration. The teaching mode has imparting basic knowledge pre-course and has internalizing and extending knowledge in class. The reason why "flipped classroom" is translated by many scholars is that it has "reverse" the teaching sequence for traditional classroom.

\section{The Root of Flipped Classroom Teaching Practice of Advanced Math.}

With the popularization of mass education, the number of people who have access to higher education has risen dramatically. The difference between each student is more and more evident and math foundation varies greatly, which confuse teachers when giving a lesson in the class. Students who are in weak foundation cannot take in what teachers say and those with good foundation lack more knowledge. Therefore, teaching mode with equal numbers and same speed has been viewed a stumbling block for learning. The teaching idea of flipped classroom leads students to individualized learning and independently study in his own pace, which gives new hope to the teachers in confusion.

In addition, the characteristics of advanced math are also suitable for flipped classroom. Advanced math features high abstraction, precise logic and wide application. The constitution system of each knowledge is closely related and goes forward one by one which offer convenience for recording teaching video. Teachers can divide content in the light of each small knowledge and then record video. In addition, in view of advanced math with high abstraction, students want to obtain deep learning better by communicating and collaborating with peers, teachers and students. In 2012, the subject of flipped classroom is mainly scientific courses such as math and science, according to relevant statistics from flipped classroom teaching by American.

\section{Modular Design of Flipped Classroom Teaching Practice of Advanced Math}

The author and teaching team have participated in many trainings related to flipped classroom teaching method, independently studied Flipped Classroom Teaching Method from MOOC, 
completed two flipped classroom teaching practices and finally have found out plan which is suitable for teaching activities for students in our school.

Team members should divide the content of the whole course according to knowledge point and ensure what knowledge every class should contain and each knowledge also should be recorded in one video. Each video should be succinct and coherent ranging from $5 \mathrm{~min}$ to $15 \mathrm{~min}$ in length. The reason why teams itself record videos is that teachers can give targeted explanation in line with the physical truth of students.

Team members assign exercises for pre-course according to the teaching content of each session. Practices for pre-course should give priority to basic questions in order to cultivate the ability of addressing problems by video learning, examine the understanding of what knowledge they acquire and then make students full of confidence by learning pre-course. At the same time, a thinking problem and a problem with comprehensive knowledge should be posed to keep students with questions in class.

The teacher uploads the teaching video via the online platform and gives a detailed pre-course activity task list three to four days before the class. There are very clear learning tasks and time nodes for each task in the task list, including the teaching videos, reference materials, pre-course exercises, and network Q\&A time for pre-course.

Teacher leads the students to sort out the knowledge points of the section and integrates the knowledge according to the progressive relationship between the videos to make students have access to the overall structure of the content of the lesson and create the knowledge system of the content of the section. This is an important process for students to integrate the fragmented content of pre-class learning.

Teachers will attach importance to the pre-school learning problems collected. The problems are generally difficult to be understand in the pre-course learning process and are difficult issues in the teaching content. After the teacher's explanation, the students' understanding and mastering the difficult points of the knowledge points of the section are deepened, and the foundation for the following classes is laid.

Teachers arranges the class exercises, and the difficulty of class exercises is greater than the precourse exercises. They center in comprehensive questions and pay attention to the combination of new knowledge and old knowledge, aiming to deepen students' understanding and application of the knowledge they have acquired. Students practice in class in the form of group cooperation, and start brainstorming, which can expand thinking and train collaboration ability via communication.

The group presentation is used to tackle the class exercises, and the teacher evaluates the group. After the process, students deepen their understanding of difficult content and clearly master the knowledge of the whole section. In the flipping process, the teacher turns from the lecturer in the classroom to the leader, and then becomes the assistant, and the student becomes the leader of the study. Through the learning process, students have a solid grasp of the knowledge they have learned and improved their comprehensive application skills. In addition, students have also received many opportunities to present themselves and their ability of communication and collaboration has also been improved.

\section{Result Analysis of Flipped Classroom Teaching Practice of Advanced Math.}

Depending on advanced math, the author and team have carried out practices of flipped classroom teaching mode for two rounds.

In the first round, the author selected a natural class of advanced math (administration) to conduct experiments. There are also 5 non-experimental classes in parallel. The author follows the above-mentioned practical activity process and design a questionnaire in the middle of the practice. The students have been investigated from the aspects of pre-course activity design, class activity design, flipped classroom and traditional classroom comparison. In terms of limited space, the author only shows the following findings. 
Table 1 Questionnaire of Flipped Classroom Learning Effect

What do you think of the result of flipped classroom compared with traditional class? (multiple choices)

$\begin{array}{lcc}\text { A Contribute to mastering knowledge for a long time } & 28 & 65.1 \% \\ \text { B More knowledge } & 14 & 32.5 \% \\ \text { C Solve problems in a more targeted way } & 32 & 74.4 \% \\ \text { D No difference } & 2 & 4.6 \%\end{array}$

Table 2 Questionnaire of Flipped Classroom Learning Effect

Whether flipped classroom is conducive to cultivating and improving selfstudy ability compared with traditional class.

\begin{tabular}{ccc}
\hline A Advantageous & B General & C Unfavorable \\
38 & 4 & 1 \\
$88.4 \%$ & $9.3 \%$ & $2.3 \%$ \\
\hline Table 3 & Questionnaire of Flipped Classroom Learning Effect \\
\hline Do you like the current flipped classroom teaching mode? \\
\hline A like & B general & C dislike \\
31 & 11 & 1 \\
$72.1 \%$ & $25.6 \%$ & $2.3 \%$
\end{tabular}

The survey results show that flipped classroom teaching mode greatly enhances the enthusiasm and initiative of students to learn advanced math. Most students agree with the design of the teaching module. They consider that flipped classroom is more conducive to cultivating and improving self-study ability and they master the knowledge acquired for a long time, and prefer to keep the flipped classroom teaching experiment.

In addition, the author also compared the test score of the experimental class students with that of the other five parallel classes. The result shows as Table 4

Table 4 Comparison Table of the first-round practice scores

\begin{tabular}{lcc}
\hline & Experimental Class & Non-experimental Class \\
\hline Average scores & 65.22 & 56.186 \\
\hline
\end{tabular}

It can be seen from the comparison of the results that the average scores of the experimental and non-experimental classes are nearly 10 points, which fully shows that the students in the experimental class can better grasp knowledge and flipped classroom teaching mode has greatly enhanced learning efficiency of students.

The results of the first round of teaching practice and the questionnaire analysis of the students have provided the author and the team great encouragement. The team summarized the experience and lessons of the first round of practice, optimized the course, and conducted the second round of classroom teaching practice in the next year. The team selected the four natural classes of the course for flipped practice, and three parallel classes are non-experimental classes, and the number of students reached half of the total number of students in the course.

After the second round of teaching practice, the teaching team conducted a comparative analysis of the test scores of the experimental class and the non-experimental class. The analysis of the results focuses on comparing the excellent rate and the low score. The results of the test results are shown in Table 5. 
Table 5 Comparison Table of the second-round practice scores

\begin{tabular}{ccc}
\hline Class & Experimental Class & Non-experimental \\
\hline Percentage (80-100) & $42 \%$ & $28 \%$ \\
Percentage (0-50) & $14 \%$ & $18 \%$ \\
\hline
\end{tabular}

From the table, we know that the excellent rate of the experimental class is much higher than that of the non-experimental class, which shows the advantages of personalized learning. Students can grasp the context of knowledge more clearly, and the knowledge of the students with good mathematics is more in-depth and firm for the knowledge in the process of course flipping is presented in an advanced way. In addition, there are fewer students with lower grades in the experimental class than those in non-experimental classes.

The results of the two-round practice indicate that students improve the initiative of learning in the flipped classroom teaching activities, play a dominant role in learning, and greatly enhance the learning efficiency. Flipped classroom teaching mode makes the classroom a stage for internalizing and expanding knowledge. It is a very suitable teaching method for mathematics as a highly abstract and rigorous discipline.

\section{Problems and Thinking in Flipped Classroom Practice of Advanced Math}

We have been faced with some problems and difficulties and further continue thinking and exploration in the process of teaching practice.

In view of the restriction on teaching platform, there are still some omissions in the process of supervising students' pre-class study. Team members can only achieve the purpose of learning well before class by mobilizing the students' learning enthusiasm, which invisibly increases the workload and work pressure for teachers. Flipped Classroom with better learning platform will exploit the advantages of teaching mode fully.

As the restriction on teaching platform and team experience in shortage, one method with more details and quantization has not been found in terms of evaluation mechanism yet. The team will continue to work hard in order to improve the evaluation mechanism of student process learning and mobilize students' enthusiasm for learning.

\section{References}

[1] Chen Qian, Li Jiaojiao, Tang Caimei. Study on the Problems and Solutions in Flipped Classroom Teaching [J]. Software Guide, 2015, (1).

[2] Wang Yajuan. Preliminary Study on Flipped Classroom Teaching Mode [J]. Shandong Trade Union Forum, 2014, (3).

[3] Zhang Jinlei, Wang Ying, Zhang Baohui. Research on Flipped Classroom Teaching Mode [J]. Distance Education Journal, 2012, (4) 